\title{
Lógicas burocráticas, notas y documentos. Las bibliotecas y el sector cultural
}

\author{
Ivana Mihal \\ CONICET, Instituto de Ciencias Antropológicas, Facultad de Filosofía y Letras, \\ Universidad de Buenos Aires. E-mail: ivana.mihal@gmail.com
}

RMA

Antropología Social

\begin{abstract}
Resumen
Este trabajo reconstruye a través de una perspectiva reflexiva de la práctica etnográfica cómo las notas y documentos exigidos para mi inserción en el trabajo de campo constituyeron las primeras aproximaciones a las políticas culturales de lectura.

El objetivo es mostrar cómo estos escritos dan cuenta de los distintos modos de abordaje de la lectura desde el ámbito del Estado, en los diferentes tipos de bibliotecas que componen ese universo en la Ciudad Autónoma de Buenos Aires, a saber: bibliotecas populares, bibliotecas públicas municipales y bibliotecas comunitarias.

Asimismo procura atender a los lineamientos que estas instituciones orientan respecto a la ciudadanía.

Este artículo trata también acerca del lugar que ocupa el registro, archivo e indagación de la información y su incidencia en las políticas culturales de lectura.

La generación y publicación de información sobre las distintos bibliotecas y organismos de cultura vinculados con ellas son instrumentos de suma relevancia en el basamento de las políticas culturales.
\end{abstract}

Palabras clave: políticas culturales de lectura, bibliotecas, escritos, informaciones, ciudadanía.

Bureaucratic logic, notes and documents. Libraries and the cultural sector

\begin{abstract}
This paper reconstructs through a reflexive perspective about the ethnographic practice how notes and documents required for my inclusion in the field turn into the first approach to cultural politics of reading.

The aim is to show how these papers are related to different reading approaches from of State field, and in the different libraries that compose that field, namely: popular libraries, publics libraries, community libraries. At the same time this paper seeks to attend the guidelines that these institutions give to citizenship.

This article is also about the importance of registration, archive and information inquiry and its impact on the cultural politics of reading. The generation and publication of information about the different types of libraries and cultural organizations related to them, are instruments of great relevance in the basement of the cultural policies.
\end{abstract}

Key words: cultural politics of reading, libraries, writings, information, citizenship.

En la Ciudad Autónoma de Buenos Aires, a nivel estatal es posible discernir dos grandes ámbitos de actuación respecto de las políticas culturales, el Estado nacional mediante la Secretaría de Cultura de Nación (SCN) y en el plano local el Ministerio de Cultura del Gobierno de la Ciudad de Buenos Aires (MCGCBA). En cuanto a la SCN incluye bajo su administración a la Comisión Nacional Protectora de Bibliotecas Populares (CONABIP), que es el organismo que mayor trayectoria tiene en el fomento de bibliotecas populares en el país. De acuerdo a los datos aportados por la Guía de Bibliotecas Populares (CONABIP 2006), existen en la Ciudad 49 bibliotecas populares adscriptas a la CONABIP. En lo relativo al MCGCBA, incluye bajo su órbita bibliotecas de distinta índole. Por un lado, están las bibliotecas públicas municipales que dependen de la Dirección General del Libro y Promoción de
Lectura (DGLyPL), con 28 bibliotecas en total distribuidas en distintos puntos de la ciudad, incluye 26 bibliotecas, la Casa de la Lectura (anteriormente denominada de la Poesía); la Biblioteca de Patrimonio y Gestión Cultural (con sede en la Casa de la Cultura) y 8 anexos infantiles. Por el otro, se relaciona con las bibliotecas comunitarias, las cuales se hallan adscriptas en el Programa "Bibliotecas para Armar" de la Dirección General de Promoción Cultural (DGPCul) y los responsables del Programa' éstas son en total 55 bibliotecas.

\footnotetext{
1 En un acto de apertura del Programa "Bibliotecas para Armar" (Ciudad de Buenos Aires, 12/05/08) se señaló que eran 55 las bibliotecas comunitarias adscriptas, cifra mayor a la que figura en la página web del GCBA éstas (http://www.buenosaires.gov.ar/areas/cultura/prom_ cultural/pops2/biblioteca).
} 
Muchos investigadores llevan a cabo minuciosas observaciones en diarios, notas y registros de campo de distinto tipo. Estos escritos desde Malinowski (1975) dan cuenta de diferentes facetas que se permean y cuelan en el proceso de investigación (Jackson 1990). Esto a la luz de los aportes y contribuciones de autores que han estudiado instituciones estatales considerándolas como dominios de lo político a través del análisis etnográfico (Abélès 2004; Pantaleón 2005); así como de investigaciones en las que los escritos y documentos (Fraenkel 1995; Fonseca 2009) se constituyen en elementos característicos y constitutivos de procesos de índole más general. Con el propósito de dar cuenta de ello, se toman en consideración algunos documentos normativos de estas bibliotecas tanto los textos escritos que fueron exigidos para mi inserción al trabajo de campo. La revisión, y análisis de los registros ha posibilitado detectar, describir y clasificar distintos modos en los cuales los documentos y notas sin tener un lugar predeterminado antes de acceder al campo. Éstos constituyeron los primeros acercamientos a los modos y supuestos sobre los cuales se construye la oferta de bienes y servicios culturales que las bibliotecas proponen a la ciudadanía. En este sentido, es clave el papel que cumplen las notas y documentos como condiciones que obstaculizan y/o viabilizan la accesibilidad de la ciudadanía a tales espacios, siendo materializaciones concretas de las políticas culturales de lectura. Este artículo trata también acerca del lugar que ocupa el registro, archivo e indagación de la información y su incidencia en las políticas culturales de lectura. La generación y publicación de información sobre las distintas bibliotecas y organismos de cultura vinculados con ellas son instrumentos de suma relevancia en el basamento de las políticas culturales.

\section{Entre la solicitud espontánea y las cartas de aval: las bibliotecas comunitarias}

El primer acercamiento a las bibliotecas comunitarias fue a partir de enviar vía mail una solicitud de entrevista con un integrante del Programa "Bibliotecas para Armar". La reunión estuvo pautada en una de las oficinas del actual MCGCBA. Mi contacto me presentó a un miembro de la coordinación del Programa. Durante el transcurso de la entrevista ambos interlocutores me dieron un sobre cerrado y etiquetado con un sticker en el que se leía "Bibliotecas para Armar", que contenía dos escritos diferentes. Uno era un tríptico en el que se difundía un ciclo de lectura (constituido por diversas actividades de narración oral para adultos y niños, proyección de películas, entre otras) que habían organizado ese año, en cuyo dorso figuraban los nombres y domicilios de las bibliotecas comunitarias y espacios de lectura adscriptos a este programa y los días que se realizaban las actividades propuestas. El segundo escrito contenía información acerca del Programa, líneas de acción y objetivos, también disponible en la página web del MCGCBA.

El Programa "Bibliotecas para Armar" de la DGPCul surgió formalmente en el 2003 cuando tomó forma definitiva, buscando promocionar la lectura a partir de su vinculación con bibliotecas comunitarias. Si embargo, según la perspectiva de unos integrantes, teniendo en cuenta el punto de inflexión que significó la crisis económica del país y el estallido de fines de diciembre del 2001, en el año 2002 la entonces Secretaría de Cultura² apuntó a establecer políticas inclusivas en el plano cultural, entre las que encontraba lugar este Programa. Entre sus lineamientos destacan aquellos relacionados con libros y literatura, pero también cuentan con la constitución de un fondo bibliográfico permanente; con la capacitación a referentes de las bibliotecas comunitarias y actividades de promoción y animación de la lectura. Junto con ello, intentan darles visibilidad pública a este tipo de bibliotecas.

Las bibliotecas comunitarias son originadas por la propia sociedad civil y pueden solicitar al Programa formar parte de él, pero no es el Programa el que las crea. Al respecto uno de sus integrantes señalaba: "lo nuestro es un servicio público del gobierno, del Estado hacia organizaciones no gubernamentales o gubernamentales que no son bibliotecas". De hecho, también así lo definía una voluntaria ad-honorem con funciones de bibliotecaria: "tenemos un convenio con "Bibliotecas para Armar" para hacer alguna actividad. Hace mucho tiempo que estamos trabajando con ellos, 2 o 3 años y siempre se hacen reuniones, porque vienen con narradores de cuentos, actividades cada tanto que programamos en conjunto". El carácter de convenio que subrayaba refiere específicamente a la inscripción de las bibliotecas preexistentes en el Programa cuando éstas solicitan ser incorporadas a él. Asimismo señalaba uno de los sentidos de "Bibliotecas para Armar", apuntalar y acompañar el proceso de sostenimiento de actividades en las bibliotecas ya constituidas como tales y dar asesoramiento para la instalación de otras nuevas.

Si bien, en un principio se trata de un modo específico de organización de un programa cultural en el que las bibliotecas no pueden ser entendidas como instituciones del Estado, con existencia autónoma e independiente del mismo, porque éste no las crea, esto resulta insuficiente para explicar como actúa la burocratización en estos espacios. El trabajo burócratico se desarrolla a partir de la diferenciación y su correlativa demostración de que las bibliotecas comunitarias constituyen un espacio no estatal. Según un integrante del Programa: "el término biblioteca comunitaria supone pensar una biblioteca urgente, digamos, lo más parecido al centro de salud como para poner una analogía, que brinda un servicio a su comunidad más próxima y, a su vez, depende de una institución mayor". La urgencia marca una necesidad, una prioridad inmediata que demanda su atención mediante la conformación de espacios no convencionales de lectura como lo son las bibliotecas comunitarias. En este sentido,

\footnotetext{
${ }^{2}$ A fines del año 2006, detentaba una posición jerárquica menor en el Estado de nivel local puesto que estaba constituido como Secretaría de Cultura del GCBA y no como un ministerio.
} 
a partir del momento en que el Estado local formatea con su intervencion a estas bibliotecas comunitarias bajo los términos de comunitario, urgente y sociedad civil, actúa burocratizando instituciones estatales pero también a estas otras organizaciones de la sociedad en general, a través del proceso de institucionalización de estos espacios en el marco de un programa.

Por otra parte, con el abordaje de "lo comunitario" lo que se enfatiza desde el Programa no es tanto el sentido de pertenencia a una común unidad, sino la relación con la proximidad, con la cercanía del servicio. Coelho (2009) plantea que el "acceso cultural" es también el acceso físico, al que define como "la posibilidad de contacto directo o por referencia con una unidad o forma cultural (existencia de un cine en una ciudad, de un laboratorio de revelado cinematográfico en un país, de una biblioteca, etc.)" (Coelho 2000: 39). La accesibilidad constituye un punto relevante de las bibliotecas comunitarias como se argumenta desde el Programa, sobre todo, en comparación con las otras bibliotecas del Estado local. Esto apela nuevamente desde el lenguaje burocrático a la apelación entre lo que es estatal y lo que no lo es. Esa distinción es construida a partir de la distribución geográfica poco uniforme de las bibliotecas públicas municipales dependientes del MCGCBA, las cuales no han priorizado barrios marginales donde la ciudadanía con menores recursos se encuentra localizada. Por ello, un integrante del Programa explicitaba que las bibliotecas comunitarias están en: "hospitales como el Santojanni, o como bares, como clubes, que tienen una biblioteca como un servicio dentro de su comunidad". Esto significa que las bibliotecas comunitarias funcionan en el marco de otras instituciones dispuestas a darles cabida, como una manera de impulsar el acceso a diversos públicos. A través de ello se reconoce la existencia de distintos niveles de ciudadanía (DaMatta 1987) y no solamente un tipo ideal de ciudadano, mediante una oferta de bienes y servicios culturales disponibles a públicos que no se orientan directamente a las bibliotecas y la lectura.

Una de esas bibliotecas comunitarias ubicada en un comedor comunitario no planteó ningún tipo de requerimiento formal para mi ingreso. Una vez allí dialogué con algunos de los integrantes del comedor, pues no había ningún encargado de la gestión de la biblioteca ni tampoco cobraban una cuota para el retiro de libros. En cambio, en otra biblioteca comunitaria la situación fue muy distinta pues dependía de una asociación civil cuyos alcances son más amplios que los de la biblioteca, dado que se dedican al tema ambiental e inmobiliario. Si bien ya había hecho algunos contactos previos con una de mis interlocutoras, cuando llegué a la biblioteca fui entrevistada por ella y por una voluntaria ad-honorem con funciones de bibliotecaria. Ambas comentaron que se desempeñaban en el área cultural de la asociación civil. Me indicaron que mediante una carta dirigida a la comisión directiva de la asociación debía contar de qué se trataba mi proyecto, explicitar mi inserción institucional y solicitar permiso para realizar allí el trabajo de campo de mi estudio. Una vez analizado todo esto en la reunión interna de la comisión directiva de la asociación civil me autorizaron a empezar a concurrir a dicha biblioteca. En resumidas cuentas se evidenciaron diferencias con las situaciones observadas en la biblioteca del comedor comunitario y de otras visitadas previamente. Pues en todos estos casos en mi presentación había especificado mis intereses en instancias verbales, no escritas, sin solicitud formal alguna.

He aquí, entonces, uno de los hitos en las notas y documentos de mi registro de campo, puesto que hubo como requerimiento la presentación de un primer escrito, consistente en una presentación formal. Pero esto también da cuenta de algunas marcas que iba a ir descubriendo en el camino de las bibliotecas como casos significativos en el estudio de las políticas de lectura. Una biblioteca conformada en tanto asociación civil requiere un número de personería jurídica que otorga el Estado, para lo que debe contar con estatutos, cierta cantidad de miembros y una comisión directiva. Constituye una entidad sin fines de lucro, que puede realizar actividades relacionadas con la oferta de bienes y servicios de distinto tipo. En el último caso, la biblioteca comunitaria ofrecía talleres a un bajo costo de restauración de papel, dibujo, pintura, entre otros. Asimismo, la biblioteca contaba con un número de asociados, lo cual implicaba el cobro de una cuota mensual reducida para el retiro de libros a domicilio (dado que por las capacidades de infraestructura no disponía de un espacio para lectura en sala). Los asociados eran inscriptos en fichas que constan de sus datos personales, entre ellos sus domicilios y teléfonos particulares. El papel que asume una "ficha de asociado" para el uso de la biblioteca comunitaria se relaciona con las valorizaciones y significaciones propias de los actores que las gestionan. La biblioteca cumplía un lugar de significación tanto para los integrantes de la asociación civil como para los "vecinos", como denominaba la bibliotecaria a quienes concurrían a dicha institución. Cotidianamente varios de ellos pasaban por el lugar, entraban a saludarla y en algunas ocasiones a retirar libros o dialogar sobre temas concernientes a la asociación civil o a problemáticas barriales. Cuando pregunté por la existencia de textos escritos acerca de la biblioteca, la bibliotecaria me proporcionó unos diarios de distribución gratuita en el barrio, editado por la asociación civil. Estos diarios en algunos números contenían notas referidas a la historia de la biblioteca, su trayectoria y sus actividades. En cambio, y a diferencia de la anterior biblioteca situada en el comedor comunitario las condiciones de admisión a asociados y otros temas pertinentes al funcionamiento, son una preocupación menos primordial para quienes gestionan este espacio en comparación con otras necesidades y demandas. La biblioteca no cuenta con actores específicamente dedicados a su atención (sean éstos voluntarios o bibliotecarios), los libros se prestan en el marco de otras actividades cotidianas. Por ese motivo desde el Programa "Bibliotecas para Armar" se había planteado reformular 
el objetivo de esta biblioteca manteniéndola abierta solo en un horario reducido. Además de que el horario de la biblioteca fuera coincidente con los días en que iba al comedor comunitario "la gente de educación" (de la entonces Secretaría de Educación del Gobierno de la Ciudad de Buenos Aires -GCBA- que realizaba apoyo escolar), quienes podrían hacerse cargo del préstamo de libros.

A partir del análisis de los distintos registros escritos es posible reconstruir la heterogeneidad de los espacios y las distintas lógicas de trabajo internas en esas bibliotecas comunitarias. Éstas pueden consistir en un espacio donde se presentan libros reunidos sobre una manta en el piso como en el caso de algunas bibliotecas en centros de salud; en una estantería con libros en el rincón de un comedor comunitario con textos para apoyo escolar; hasta una biblioteca con préstamo domiciliario y pago de cuotas. Es clave entender que las bibliotecas comunitarias se fueron convirtiendo de acuerdo a sus trayectorias particulares en espacios que se sostienen sobre la base de condiciones disímiles, que dan cuenta de una complejidad y variedad institucional. A mayor grado de institucionalización de las bibliotecas comunitarias se requieren recorrer una serie de circuitos para su abordaje, de lo que dan cuenta las notas formales solicitadas que atestigüen la llegada de alguien para realizar un estudio, entrevista, investigación. Pero también existen otros espacios comunitarios donde la ausencia de papeleos (tanto para mi labor antropológica como para la solicitud del préstamo de libros) pone de manifiesto cómo los vínculos informales forman parte de las condiciones de existencia de estas bibliotecas.

El Programa "Bibliotecas para Armar" interviene poco en la producción de esas lógicas particulares de las bibliotecas comunitarias. Su eje está puesto en asistir en el proceso de instalación de las bibliotecas comunitarias en distintos puntos de la Ciudad y en la realización de actividades conjuntas de promoción de la lectura. El Programa actúa asegurando que libros y otros materiales de lectura estén disponibles en los servicios y en la oferta cultural que pueden brindar las bibliotecas comunitarias. Pero las modalidades a través de las cuales esto se lleva a cabo en la práctica concreta varían según las pautas valorativas de quienes gestionan las propias bibliotecas comunitarias. La presencia de notas y documentos, o de soportes materializados en la figura de "carnet" para la solicitud y/o retiro de libros de la biblioteca, es una opción que cada una de ellas define. Los requisitos exigidos a concurrentes o asociados también dependen de sus criterios concretos. El Estado local mediante el Programa "Bibliotecas para Armar" no se constituye como un actor de injerencia determinante en tales asuntos, su papel está más ligado al de facilitador de ese acceso. El cómo y desde dónde de esa accesibilidad queda librado principalmente a las propias bibliotecas comunitarias, definiciones en las cuales el Estado no está implicado de manera directa, sino tangencialmente. Las lógicas burocráticas regulan a estas instituciones en la medida en que ellas son apoyadas por las instancias estatales, bajo un gran esfuerzo de demarcar socialmente lo que es estatal y lo que no lo es y de eufemización de la intervención estatal.

\section{Presentaciones, mails y algo más: las bibliotecas populares}

En cuanto a las bibliotecas populares, las tratativas telefónicas y vía mail de comunicarme con la CONABIP acorde a los datos que figuran en su página institucional y solicitar una entrevista habían sido en vano. Luego de insistir, alguien de comunicación accedió a recibirme quince minutos en una oficina de la que entraban y salían constantemente colegas suyos. Me entregó un tríptico que sintetizaba referencias institucionales: qué era la CONABIP, sus políticas y actividades, qué era una biblioteca popular, fotografías de algunas de ellas, y se mencionaba la legislación concerniente a éstas. Esa información no difería de la que se podía obtener por medio de la página web del organismo, ni de la que me fue suministrada de modo casi mecánico y de memoria en ese diálogo.

Luego de conseguir la apertura a este nuevo campo por medio de otra interlocutora me apersoné en la sede de la CONABIP, que ocupa un edificio propio, para dialogar con ella. Durante más de dos horas respondí a los interrogantes que mi interlocutora, recién ingresada a esta entidad, planteaba con respecto a la promoción de la lectura. A su vez, fui abriendo preguntas y solicitando, muy de vez en cuando, materiales de archivo, memorias institucionales, evaluaciones. Documentos de índole pública que facilitarían conocer y analizar las políticas culturales de lectura y la gestión de este organismo, en sus casi 140 años de existencia. Pronto comprendí que tales documentos eran mayormente inexistentes o inaccesibles y que los pocos que estaban publicados daban cuenta de cuestiones aisladas y fragmentarias. También me facilitó un CD con el plan que la CONABIP había elaborado con el Centro Regional para el Fomento del Libro en América Latina y El Caribe (CERLALC) y el mismo tríptico que me habían dado en el área de comunicación del organismo y unas revistas (tituladas Bepé) que edita CONABIP. En encuentros posteriores con esta interlocutora volví a repreguntar acerca de ciertos documentos disponibles a investigadores y me dio un libro sobre "Bibliotecas Populares Argentinas" con ilustraciones de bibliotecas de distintas regiones del país y una "Guía de Bibliotecas" elaborada en el 2006.

Recién algún tiempo después me percaté que los documentos tomaban cuerpo otra vez en mi investigación, esta vez como instrumentos que representan modos por medio de los cuales el Estado procesa las informaciones. Mi interlocutora trabajando en una entidad cultural de dominio estatal carecía para su quehacer cotidiano de documentos tales como organigramas, memorias, formulación escrita de lineamientos políticos y técnicos 
a seguir por cada nueva comisión directiva que asume la conducción de CONABIP cuando se renuevan sus autoridades, etc. Junto a estos escritos también son necesarias otras informaciones que posibiliten diseñar indicadores culturales específicos, siendo que éstos son relevantes para la gestión pública de políticas culturales, como afirma Calabre (2009). Si bien todas las reparticiones culturales del Estado local y del Estado nacional efectúan informes anuales de gestión éstos no se encuentran disponibles a la ciudadanía en general. Recién en estos últimos años la CONABIP ha elaborado un "Informe de Gestión y Resultados 2003-2007", publicado en septiembre del 2007, a fin de dar un balance de lo realizado por el organismo cuando culminaba el mandato de las autoridades y era el momento de elegir nuevos representantes, con lo cual se visualiza que las publicaciones constituyen una orientación clara cuando las voluntades políticas así lo resuelven. De la misma forma, la SCN ha puesto a disposición pública (a través del Sistema Nacional de Información Cultural de la Argentina -SINCA-) una serie de documentos, estudios e informaciones que apuntan a cubrir algunas de tales insuficiencias.

En las propias bibliotecas populares la circulación de informaciones también es un aspecto relevante. En el marco de una entrevista una bibliotecaria hizo un paneo de la situación general de la biblioteca popular en la que desarrollaba su labor destacando, a su vez, que era miembro de la comisión directiva y que desempeñaba funciones ad-honorem de gestión, y de contactos con la CONABIP. Esa biblioteca popular contaba además con otra bibliotecaria para cumplir funciones internas, tal como explicó: "todo lo que tenga que ver con los chicos y la biblioteca lo tratás con X (la bibliotecaria), todo lo relacionado con la CONABIP, cuestiones más teóricas y de promoción de la lectura lo tratás conmigo". Estas diferenciaciones implican un ordenamiento claramente definido de distintas incumbencias laborales. Asimismo, la diferenciación de lo tratable con ella o con la otra bibliotecaria se vincula con la complejidad de las bibliotecas populares como iniciativas sociales que reciben apoyo del Estado. Para que CONABIP reconozca a una biblioteca como tal es condición imprescindible contar con personería jurídica y como cualquier asociación civil establecen las funciones de sus integrantes. Las decisiones al interior de cada una de las bibliotecas populares pasan por los integrantes de las propias asociaciones civiles que las gestionan. En esta biblioteca, para ser socios los menores de edad (que eran la mayoría del público) requieren ir acompañados de un adulto la primera vez, y luego pueden solicitar por sí solos libros en la biblioteca y/o llevárselos en préstamo a sus hogares. El domicilio y otros datos se registran en una carpeta de socios en el que cada uno de ellos se inscribe en una ficha. No es necesario presentar documentos que señalen la veracidad de los datos señalados. Tampoco se requiere en esta biblioteca del abono de la cuota que generalmente exigen las bibliotecas populares. Esta fue una decisión interna de la comisión directiva para, como explicaba uno de sus integrantes: "no generar obstáculos" a quienes quisieran acercarse a la biblioteca. De este modo, desde la biblioteca se procuran establecer condiciones de admisión a sus asociados que abreven al acceso a la disponibilidad de su oferta cultural.

Al cabo de un tiempo de ir a la biblioteca, la bibliotecaria con la que había mantenido mi primera entrevista preguntó cuál era mi marco teórico, y me pidió que se lo entregara por escrito. Mi interlocutora, también ligada a temas concernientes con las bibliotecas del sector educativo conocía a la antropóloga francesa Petit (1999). Esta autora aborda en sus estudios las prácticas de los lectores en Francia y ha sido invitada en numerosas oportunidades a brindar conferencias en eventos educativos de la Argentina. Me preguntó si tenía en cuenta los trabajos de Petit y qué otros autores "me servían" para investigar el tema de bibliotecas. Esto marcaba una referencia importante, encarnando la situación que se da cuando con quienes nos relacionamos en el campo "son nuestros vecinos" (Ginsburg 2007). Puso en evidencia que estaba siendo interrogada críticamente por mis propios interlocutores, como sostiene Rosaldo (1989): "el análisis debe aceptar que sus objetivos de análisis también son sujetos analizantes que interrogan de forma crítica a los etnógrafos -sus escritos, su ética y política-" (Rosaldo 1989: 31). En ese cuestionamiento entraban a jugar los escritos. Estos escritos actuaron como un elemento de negociación en el trabajo de campo, pero sobre todo, dieron cuenta de otros de los modos en que los textos muestran su incidencia en las bibliotecas.

En cambio, en otra biblioteca popular no debí presentar ninguna nota o escrito, simplemente me presenté en un evento en el cual se festejaba el aniversario del barrio y en el que la biblioteca era una de las instituciones involucradas. Me acerqué a un puestito donde se leía en un cartel de colores Biblioteca Popular y comencé a dialogar con quienes estaban presentes, posteriormente uno de ellos sería uno de mis principales interlocutores de campo. Éste me derivó a la bibliotecaria por medio de llamados telefónicos para acordar una "visita a la biblioteca", como refirió en ese momento. No obstante, el día pautado la bibliotecaria no estuvo presente en la entrevista sino que estuvieron mi interlocutor inicial y el presidente a cargo de la biblioteca popular. Una vez más, se apreciaban ciertas jerarquías y posiciones internas entre los actores de una biblioteca en tanto asociación civil, marcándose distinciones y clasificaciones en las tareas y funciones. Denotándose que los miembros de la comisión directiva eran quiénes podían dar cuenta de las cuestiones generales de la biblioteca. En contraste, la bibliotecaria se concentraba en la atención al público y los aspectos relacionados con el patrimonio bibliográfico. Asimismo en esta biblioteca popular se exigía (aunque con excepciones para quiénes no pudieran costearlo) el pago de una "módica" cuota mensual, como mencionó uno de los integrantes de su comisión directiva. 
En la aproximación al campo es posible advertir cómo la modalidad de trabajo de una asociación civil cobra sentido aún en los detalles más mínimos en lo cotidiano. La institucionalidad de las bibliotecas populares dependientes de la CONABIP es la más relevante de todos los tipos de bibliotecas analizados. La CONABIP es la encargada de "orientar y ejecutar la política gubernamental para la promoción de la lectura popular y el desarrollo de las Bibliotecas Populares". La Ley $23.351^{3}$ de Bibliotecas Populares vigente desde el año 1986; establece su constitución como asociaciones civiles de carácter gratuito sostenidas “... básicamente por sus socios- con el fin de brindar información, educación, recreación y animación socio-cultural mediante una colección bibliográfica y multimedial de carácter general y abierta a todo público." ${ }^{4}$. Comparadas con otras infraestructuras vinculadas a la SCN (cfr. museos, teatros, cines, etc.), las bibliotecas populares son las instituciones más presentes y mejor distribuidas en todo el país (Bayardo 2008) y en la Ciudad de Buenos Aires. Aún cuando las bibliotecas populares no sean instituciones estatales, es protagónico el papel que juega el Estado nacional a través de la CONABIP en el otorgamiento de beneficios y subsidios para el sostenimiento de las bibliotecas populares (infraestructura, recursos humanos, patrimonio bibliográfico, entre otros). Estos aportes se desarrollan sobre la base del cumplimiento de ciertos requerimientos de regularidades y de trámites al día por parte de las bibliotecas (con la constatación escrita de su redacción). Desde el punto de vista de los miembros de las comisiones directivas de las bibliotecas populares los trámites son considerados "engorrosos" y privan de la obtención de subsidios a gran parte de estas bibliotecas. Las trabas en este último caso, están puestas desde nivel central por las condiciones exigidas para el otorgamiento de subsidios a las bibliotecas, lo cual hace que de casi 2000 bibliotecas populares en todo el país, menos de la mitad de ellas logren obtenerlos ${ }^{5}$. Sin embargo, la CONABIP no establece regulaciones administrativas referentes a las informaciones y exigencias en el uso de notas y documentos de las bibliotecas populares. La CONABIP no actúa de forma centralizadora con respecto

\footnotetext{
3 La Ley 419 (1870) dio origen a dicha Comisión para "fomentar la creación y el desarrollo de estas instituciones, constituidas por asociaciones de particulares, con la finalidad de difundir el libro y la cultura". En 1986, esta ley fue reemplazada por la Ley 23.351, la cual estableció los objetivos y el funcionamiento de la CONABIP.

${ }^{4}$ Actualmente la página de la CONABIP presenta un conjunto de informaciones disponibles en el sitio www.conabip.gov.ar, concernientes a aspectos institucionales del organismo, a informaciones de eventos vinculados con cuestiones inherentes al funcionamiento técnico administrativo de las bibliotecas como a la promoción del libro y la lectura, y a normativas vigentes en el territorio argentino que atañen a las bibliotecas populares.

${ }^{5}$ Generalmente mis interlocutores de campo mencionaban alrededor de 950 bibliotecas populares que cumplen con los requisitos, cifra estimativa que puede sufrir modificaciones anualmente pero no de carácter sustantivo, dado que cada dos años cuando se realiza el Encuentro Nacional de Bibliotecas Populares (que se lleva a cabo en la Ciudad de Buenos Aires), suelen participar del mismo aproximadamente esta cantidad de instituciones.
}

a las decisiones de cada una de las bibliotecas, pues éstas no son entidades estatales. Ese circuito burocrático "engorroso" que señalan los integrantes de las bibliotecas populares no genera desde la CONABIP per se una norma de exclusión de la ciudadanía a las bibliotecas. Los mecanismos a través de los cuales textos escritos son exigidos obedecen a las decisiones de los integrantes de la comisión directiva de cada biblioteca popular y a los estatutos bajo los cuáles éstas se amparan

\section{De normas y autorizaciones: las bibliotecas públicas municipales}

Con las bibliotecas públicas municipales, tras otra serie de azares del trabajo de campo me contacté mediante correo electrónico con un integrante del nivel central de la DGLyPL que accedió a darme una entrevista, aclarándome que había ingresado a su puesto recientemente con la nueva gestión gubernamental del GCBA (con la asunción de Macri como jefe de gobierno). En la entrevista, los interrogantes estaban relacionados tanto a su área de trabajo como a la DGLyPL en general. No obstante ante consultas concernientes a la DGLyPL se levantaba y me decía "esperame un momento", iba hasta el teléfono y preguntaba algunas de las respuestas. Esta especificidad que impide una mirada más integral no era suya exclusivamente sino que mostraba una forma de trabajo de esta institución estatal. La información que él manejaba era parcial y circunscripta a las incumbencias de su dirección. La DGLyPL está constituida por 4 Direcciones: la Dirección General, la Dirección de Programación y Difusión Cultural, la Dirección de Gestión Operativa, y la Dirección de Coordinación Técnica. Cada una de ellas se encarga de distintos dominios vinculados a las bibliotecas públicas municipales.

La DGLyPL forma parte de una de las seis Direcciones Generales que componen la Subsecretaría de Cultura del MCGCBA, cuyas funciones principales consisten en supervisar y coordinar la difusión y el acceso del patrimonio de las bibliotecas públicas municipales. Esto significa que en su carácter de Dirección General se encarga "de la planificación y ejecución de todos los temas de incumbencia en relación a la Red de Bibliotecas de la Ciudad, a fin de difundir la promoción de la lectura y facilitar el acceso a la comunidad de las obras que constituyen su patrimonio", como consta en la página web del organismo. Cada una de las Direcciones incluidas bajo esta Dirección General tiene competencias y dominios específicos, conformando así áreas diferenciadas y delimitadas. Según el "Informe Final de Auditoría" (AGCBA 2002), la Dirección de Programación y Difusión Cultural tiene a su cargo específicamente la programación de actividades de promoción del libro y la lectura, tales como conferencias, eventos literarios, teatrales, entre otros. La Dirección de Gestión Operativa es la encargada de elevar y controlar el presupuesto anual, la supervisión de la conservación y refacción edilicia de las bibliotecas, del control del personal y de "los bienes patrimoniales 
de la repartición". Las funciones de la Dirección de Coordinación y Técnica consisten en "determinar las características y las necesidades bibliográficas de acuerdo con la distribución geográfica de la población; planificar la adquisición y suministro de libros a las distintas bibliotecas del Gobierno de la Ciudad de Buenos Aires".

Antes de retirarme de esta reunión, le pregunté si tenía textos escritos sobre la DGLyPL y/o sobre las bibliotecas públicas que pudiera facilitarme. Buscó en una repisa un sobre que contenía los informes de dos encuestas sobre hábitos de lectura en habitantes de la Ciudad de Buenos Aires realizadas por esta Dirección en los años 2004 y 2005 . Cuando me los entregó dijo: "te pido por favor que lo lleves para fotocopiar y en la semana me lo alcances porque no tenemos otra copia". En cuanto a documentos referidos a la propia DGLyPL sólo contaban con unos trípticos sobre las actividades bimestrales que realizaban, a saber: presentaciones de libros, charlas con especialistas, ciclos de cine y literatura, conciertos de música, espectáculos de títeres y teatro, entre otras. Estos folletos se envían a las bibliotecas públicas municipales para informar al público sobre la actualización de las actividades propuestas por la Dirección de Programación y Difusión Cultural. Posteriormente, en las entrevistas que mantuve con integrantes de las bibliotecas pude constatar que tales folletos se distribuyen tardíamente, con lo cual hay muy poca difusión al respecto. También me dio para fotocopiar un libro realizado desde una perspectiva histórica (Miranda 1996) cuando la DGLyPL aún se denominaba Dirección General de Bibliotecas en el marco de la entonces Municipalidad de la Ciudad de Buenos Aires, actual GCBA ${ }^{6}$.

Todo esto se relaciona con una lógica de funcionamiento en el que las producciones, usos y publicaciones de información relativas a las bibliotecas y sus análisis resultan centrales, pues como han expresado Das y Poole "...la mayor parte del Estado moderno está construido a partir de prácticas escritas" (Das y Poole 2008: 25). Al respecto O'Donnell (1984) subraya que los inconvenientes para la obtención de los documentos y materiales escritos que el Estado produce constituyen también parte de esos recursos de control. En las bibliotecas públicas municipales se construyen cotidianamente informaciones y registros de diversa índole (elevación de cartas a la Dirección General sobre pedidos, cambios, programaciones, etc.). Esas informaciones y registros se elevan a la DGLyPL, la que a su vez informa sus directivas a las bibliotecas (nuevas reglamentaciones, notificaciones, respuestas a las consignas planteadas por las bibliotecas a su cargo,

\footnotetext{
${ }^{6}$ Por medio del Decreto $n^{\circ} 1.988 / 00$, el Poder Ejecutivo del Gobierno de la Ciudad de Buenos Aires modificó la estructura organizativa que había sido aprobada por Decreto $N^{\circ} 1.361 / 00$. En el mismo se modifica la denominación de la Dirección General de Bibliotecas, por "Dirección General del Libro y Promoción de la Lectura", dependiente de la Subsecretaría de Acción Cultural de la Secretaría de Cultura. Luego por el Decreto $N^{\circ}$ 654/01 se suprime la Subsecretaría y se transfiere esta Dirección General a la Subsecretaría de Patrimonio Cultural dependiente de la entonces Secretaría de Cultura.
}

etc.) también mediante escritos. Sin embargo, esto no significa que esas notas y documentos sean accesibles a través de su publicación a la ciudadanía, o que puedan ser consultados en archivos de la DGLyPL o del MCGCBA. Generalmente la difusión de informaciones se hace mediante la página web del GCBA. Esos escritos accesibles en páginas web tienden a presentar información descriptiva (cfr. como los informes de encuestas que me fueron entregados), o parcial sobre aspectos puntuales.

En un segundo momento pude por otra vía contactar a alguien de la Dirección de Coordinación y Técnica, que trabajaba en la DGLyPL desde hacía muchos años y pertenecía a la planta permanente de empleados estatales. Procuré, nuevamente, conseguir textos escritos relativos a la DGLyPL. Los avances consistieron en estadísticas del mes de agosto de 2008 donde constaban los registros del número de socios, de los libros consultados en sala y circulantes en domicilio. Asimismo en estas estadísticas constaba el número de concurrentes en dicho mes a cada una de las bibliotecas públicas municipales. También me entregaron estadísticas discriminadas por sexo y edad para el mismo mes y una estadística que detallaba el total anual correspondiente a 2007. Sin embargo, en las entrevistas realizadas posteriormente con integrantes de las bibliotecas surgió que algunos de ellos "dibujan" los datos estadísticos. Las reparticiones si no convocan a grandes cantidades de asociados temen su cierre y la pérdida de los puestos de trabajo de sus empleados. En esas circunstancias, los elementos escritos que se presentan distorsionados ante, por ejemplo, la Dirección General pueden ser considerados en cierta medida como otras prácticas y concepciones que devienen centrales para algunos actores en pos de procurar el fomento de la lectura desde las bibliotecas públicas municipales, y para asegurar el sostenimiento y sobrevivencia de éstas en el sector cultural.

Ahora bien, esas informaciones se tornaron instrumentos poco confiables. Las decisiones que devienen en el ocultamiento de cifras revelan que aún falta establecer tales datos en el marco de una concepción relacionada con la sistematización del trabajo de la función pública (cfr. monitoreo y seguimiento de las acciones efectuadas, evaluación de los resultados de tales acciones, etc.). Se reiteraba en otro nivel de responsabilidad la omisión en la publicación de organigramas, modificaciones en las estructuras internas, memorias institucionales de la DGLyPL, documentos sobre políticas, programas o planes de promoción de lectura y/o formación de público lector. Su ausencia marcó grandes vacíos, pero también hitos claves en mi investigación, que dan cuenta cómo se conciben y funcionan las instituciones estatales desde la lógica burocrática.

La construcción de esas lógicas está particularmente asociada con la presencia de notas y documentos, en tal sentido Weber señala que la estructura burocrática del Estado se basa en la existencia de documentos escritos, 
pues "la evolución específica de las tareas administrativas ha sido siempre terreno adecuado para la burocratización de una administración" (Weber 1985: 185). También sostiene que el ocultamiento de los conocimientos y acciones es una tendencia de la administración burocrática que se vincula con los conocimientos expertos y especializados sobre los cuales se sustenta la burocracia. En efecto, tiempo después por una red de relaciones personales, una compañera de estudio me refirió haber participado en un "Informe Final de Auditoría" (AGCBA 2002) sobre la DGLyPL. Este informe fue realizado por la Auditoria General de la Ciudad de Buenos Aires, órgano autárquico, y se focalizaba en una auditoría de gestión del año 2002. Específicamente evaluaba "la adecuación de gestión de los recursos al cumplimiento de los objetivos institucionales y del programa en términos de eficacia y eficiencia" (ídem). Sin embargo, dicho Informe nunca fue mencionado en las entrevistas que mantuve con integrantes del nivel central de la DGLyPL. Frente a esta situación decidí ingresar al portal web de la Auditoria General, servicio disponible tanto para personal ligado a entidades gubernamentales como para cualquier ciudadano que desee conocer los boletines oficiales donde se detallan los informes de las auditorias llevadas a cabo. El esfuerzo fue en vano, tuve que comunicarme telefónicamente con mi compañera quien me detalló los dígitos que componían el número de proyecto (un número que es de carácter interno y exclusivo para el personal de la AGCBA) para realizar la búsqueda en la página web. Asimismo, en esa comunicación, reconstruida a posteriori en mi cuaderno de campo, añadía: "la DGL es una burocracia terrible, no están acostumbrados a dar ningún tipo de información (...). A nosotros como parte de la Auditoria nos resultó difícil conseguir los datos, no me imagino a vos...!". Esto pone el acento en una cuestión que subyace a las instituciones, los seguimientos y evaluaciones a los que se ven sometidos se valoran más como negativos que como instrumentos que posibiliten realizar mejoras en aquellos aspectos que no consiguieron alcanzar las metas propuestas. Los parámetros de eficacia y eficiencia constituyen el eje de los informes que resultan en "críticas", de ahí su tendencia al escamoteo de información (e incluso su ocultamiento como enfatiza Weber).

Cuando se plantea que las bibliotecas públicas municipales favorecen el acceso a la información esto no se reduce a la disponibilidad de patrimonio bibliográfico, también involucra el acceso a estos otros tipos de informaciones sobre actividades, normativas, presupuestos, políticas, y cualquier otra inquietud solicitada. Sin embargo, el hecho de que estas bibliotecas sean instituciones públicas no las hace menos suceptibles de ser reguladas y orientadas por principios ligados a intereses diversos, con límites hacia el exterior, con reglas, prácticas y valores de funcionamiento, en donde no todo esta escrito ni formalizado, los que actúan con gran fuerza orientadora de las acciones de esas instituciones. Las trabas para acceder a documentos públicos y consultar materiales escritos acerca de las instituciones del Estado, incluyendo organismos autónomos de control expresan una constante en el manejo de la información, cuya ausencia se vuelve significativa. A partir de esto, intenté localizar también mediante internet en la Auditoria General de la Nación (órgano que audita las entidades del Estado de nivel nacional) algún informe sobre la CONABIP o sobre temas ligados a la promoción del libro y la lectura en la SCN, pero no encontré nada al respecto.

Otro punto nodal donde los textos escritos tomaron presencia en relación a la DGLyPL lo constituyó mi autorización para ingresar a las bibliotecas dependientes del organismo. Desde la Dirección de Coordinación y Técnica me solicitaron que presentara una carta pidiendo permiso a la Directora General de la DGLyPL para realizar un estudio señalando anclaje institucional que tenía. La DGLyPL elevó una nota a mi nombre con un número de resolución diciendo que tenía aval para realizar "visitas a las bibliotecas". También me imprimieron el listado de bibliotecas públicas municipales indicándome los nombres de los jefes/as a cargo de cada una. Al momento de entregarme este listado, mi interlocutora que se desempeñaba en la Dirección de Coordinación y Técnica fue señalando cuáles de estas instituciones estaban cerradas, y terminó diciendo: "Ilevá siempre esta nota porque los jefes de biblioteca son gente complicada". A pesar de contar con esa resolución en algunos casos los jefes/as me preguntaban si yo había hablado con la Directora General (el cargo más jerárquico dentro de la DGLyPL) y quién era la autoridad que había firmado la nota. En una ocasión llegué y un jefe de biblioteca aún con nota en mano llamó a la DGLyPL para constatar la veracidad del permiso que le mostraba. El cuestionamiento refería a la firma que autorizaba mi carta de aval, pues ésta había sido refrendada por la parte de la Secretaría Técnica de la Dirección de Coordinación y Técnica y no por la Dirección General de la DGLyPL. En otra de las ocasiones uno de los jefes la fotocopió para cuando tuviera que dar cuenta de las "actividades" ante la DGLyPL, puesto que yo había pasado por allí y podía ser considerada como parte de ese ítem. En algunos casos ni con nota en mano y llamado por teléfono con anticipación me atendían los jefes sino que derivaban a personal subalterno a responder preguntas. Esto, sin embargo, daba más apertura para abrir los interrogantes hacia cuestiones cotidianas que generalmente los jefes obviaban en sus respuestas (horarios, funciones que cumplían, tipos de contratación, disponibilidad de recursos en la biblioteca, etc.). Finalmente, en otra biblioteca el jefe a cargo me dijo: "acá aceptamos a todos los que quieran venir a laburar, lo que digan de la Dirección General no nos importa".

Además de los usos y sentidos que adquieren las notas para los integrantes de las bibliotecas públicas municipales, éstos revelan tensiones existentes entre ellos y la Dirección General de la DGLyPL. Estas conflictividades, tensiones y articulaciones evidencian que el Estado no es 
algo dado sino construido (Abrams 1988), por lo que no puede entenderse como un actor homogéneo (Rubim, et.al. 2006) ni monolítico. Estas tensiones dan cuenta de perspectivas, opiniones y prácticas distintas tanto entre los actores de nivel central de la DGLyPL con las bibliotecas, como de las bibliotecas públicas municipales entre sí. Al respecto, en una de estas bibliotecas, una empleada mencionó que se manejaban en el funcionamiento cotidiano con el Reglamento Interno de Bibliotecas, entregándomelo para ir a fotocopiarlo. Sin embargo, al salir de la institución, ya en la vereda, escuché que su jefe/a le gritaba violentamente. Seguidamente pidió que le devolviera dicho documento, agregando: "dice X. que lo tenés que pedir en la DGL, te lo tienen que dar ellos. Nosotros no te lo podemos dar porque es riesgoso...". La empleada se mostró acongojada y la magnitud del hecho coartó la posibilidad de seguir realizando el trabajo de campo en esa biblioteca: la máxima autoridad de la institución (jefe/a) mostró reticencias para tal fin. Los modos de concebir la información son disímiles para los jefes/as y empleados de las bibliotecas, pues el jefe de esta biblioteca en cuestión decide obstaculizar el acceso de información. La forma fue derivando la solicitud del mismo a la autoridad jerárquica de la que depende, la DGLyPL.

Luego de este suceso empecé a observar que en ninguna de las bibliotecas públicas municipales se exhibía o ponía a disposición para consultar por otro medio, el Reglamento Interno. Pero ¿hasta qué punto los reglamentos y normas que rigen el accionar de instituciones estatales pueden ser concebidos exclusivamente como de carácter interno o dominio privado de las mismas? Conseguí ese reglamento mucho tiempo después, en otra biblioteca donde me lo prestaron sin objeciones. Sin embargo, las dificultades en su obtención implican modos de comprender la información pública sobre servicios y bienes, y de los pormenores detallados del trabajo de campo surgen distintas cuestiones. Aún cuando existen datos consignados en informes que se realizan anualmente y en otro tipo de documentos (evaluaciones de actividades, balances, etc.), el manejo de dicha información se hace como si fuera privada y no pública. Paradójicamente en una institución como una biblioteca en la cual uno de sus objetivos es brindar información al público que concurre a ella, el suministro de información resulta restrictivo y en ocasiones denegado. Estas situaciones dan cuenta de distintas significaciones y prácticas que se ponen en juego en los distintos actores que se encuentran vinculados con las bibliotecas públicas municipales y que orientan las modalidades heterogéneas en el uso y acceso de las normas e informaciones. Pero también esas concepciones y acciones muestran cómo aún en instituciones dependientes del mismo sector cultural, coexisten condiciones diferenciales (según las circunstancias, el contexto y los propios actores que las gestionan cotidianamente), de acercar la lectura a distintos sectores sociales y al público con que se vinculan. En ese afán de promocionar la lectura algunos actores flexibilizan en sus rutinas laborales requisitos formales que la ciudadanía debe demostrar ante el Estado local para el uso de bienes y servicios simbólicos bajo su dominio, en pos de revalorizar y reorientar sus instituciones a tal fin.

Según consta en el documento denominado "Actualización del Reglamento de la Dirección General del Libro y Promoción de la Lectura"7, único texto de estas características relevado en ese ámbito, los requisitos formales para solicitar una credencial de lector son varios. Primero, "la solicitud del carnet de lector se realizará mediante el llenado de un simple formulario, la presentación de un documento nacional de identidad (DNI), agregando el último recibo de un servicio público (luz, gas, teléfono), donde se verificará el domicilio real". Segundo, para completar este trámite es necesario "aportar datos de un co-responsable de 21 años que no viva en el mismo domicilio, y del cual debe presentarse un documento de identidad y la última factura de uno de los servicios públicos habituales". Las condiciones exigidas resultan difíciles de franquear, por ello un jefe de una biblioteca planteaba: "es una locura que se pida todo esto para asociarse, yo ya lo hablé con la gente de la Dirección y aunque me lo exijan no lo voy a pedir y ya salí de garante de casi todo el barrio". Esto va contracorriente de lo que estipula el nivel central a través de la DGLyPL. De este modo, se tensiona el "valor pragmático" (Fraenkel 1995: 85) que tiene un documento como la credencial de lector para el origen y mantenimiento de una norma. Según este jefe, tales exigencias limitan el acceso de la ciudadanía cercana al barrio que vive en asentamientos irregulares y precarios, que no cuentan con servicios públicos o los tienen de manera ilegal. Por lo cual en su biblioteca habían decidido (él y su personal) dar en préstamos libros sin el pedido del documento nacional de identidad, lo cual había sido viabilizado por dicho jefe ya que: "sino las bibliotecas pasan a ser sólo de los socios y no es así, si hay pérdida de libros que el Estado las cubra!". En esta biblioteca se procura dar cabida a sectores excluidos, cuestionándose la norma de exigencia de una documento como instrumento de "control", de registro de aquellos que quieran hacer uso de la biblioteca, en sintonía con ello agregaba: "en la villa al ser de condición precaria no tienen recibos a nombre de ellos, ni tienen documento o tienen documento en trámite. Entonces ahí hay un proceso de discriminación, no tiene documento nacional, que pasa ahí...". La inclusión está siendo pensada más desde los actores que gestionan las bibliotecas públicas municipales que desde articulaciones y acuerdos con el nivel central del Estado, en este caso la DGLyPL, al cual responde esta institución. Los lineamientos de la DGLyPL continúan proclives a mantener las condiciones exigidas (que constan en dicho reglamento interno de bibliotecas)

\footnotetext{
7 Este documento establece las pautas para el desenvolvimiento de las bibliotecas. Según consta en el Informe de gestión de Auditoria del GCBA del 2002 este Reglamento fue puesto en funcionamiento 3 de octubre de 2001 en virtud del Decreto No 1.089/1977. No obstante, dada las imprecisiones de los jefes/as y empleados de bibliotecas queda la duda si ha sido o no modificado con posterioridad.
} 
sin mayores alcances respecto a una ciudadanía más inclusiva. Las cristalizaciones de estas condiciones terminan naturalizando a un supuesto público lector cuyas características socioeconómicas y educativas se han uniformizado a la ciudadanía en general sin atender a las desigualdades existentes.

Los mecanismos de préstamos de libros dan un primer indicio en relación a los supuestos y premisas que tiene la DGLyPL, dando cuenta de algunos aspectos constitutivos de los modos y concepciones referentes a quiénes se ofrecen los bienes y servicios culturales. Las bibliotecas públicas municipales no están pensadas prioritariamente para los sectores más desfavorecidos. Esto se visualiza en los documentos requeridos, los impuestos, como de la disponibilidad de tiempo para asegurar la figura de un garante para realizar las inscripciones de nuevos asociados a la biblioteca. La falta de modificaciones en las condiciones exigidas para ser acreditado por parte del Estado local como "lector", muestra que "tendemos a considerar que los documentos sao papéis congelados no tempo e, no entanto eles estão en constante mudança" (Fonseca 2003: 66). La Actualización del Reglamento Interno de Bibliotecas no ha tenido en cuenta que las condiciones de exigencia son elementos dinámicos. Precisamente por ser dinámicos pueden ser revisados a fin de procurar la inclusión de los sectores aun excluidos en las bibliotecas, el acceso a la información y la concreción de derechos culturales y de la diversidad cultural de la ciudadanía.

Las lógicas burocráticas construyen demarcaciones y clasificaciones en las propias bibliotecas, entre distintas bibliotecas que dependen del mismo organismo, como hacia el exterior. Esos límites, aunque no estén formalmente escritos actúan reforzando valores y orientaciones en las acciones que se desarrollan desde estas instituciones, que aún siendo públicas implican intereses disímiles para los actores que realizan sus quehaceres en ellas o para ellas desde el sector cultural estatal.

Buenos Aires, 2 de mayo de 2011.

\section{Agradecimientos}

Este artículo es una reformulación de uno de los capítulos de mi tesis doctoral en antropología (2011). FFyL. UBA.

\section{Referencias Bibliográficas}

Abélès, M. 2004. Identity and Borders: an Anthropological Approach to EU Institutions [en línea]. Twenty-First Century Papers. Century Studies. University of Wisconsin, Milwaukee. http://www.21st.uwm.edu. (Última consulta: 18/12/2008).

Abrams, P. 1988. Notes on the Difficulty of Studying the
State. Journal of Historical Sociology 1 (1): 58-87.

Bayardo, R. 2008. Políticas culturales en Argentina En: Rubim, A. y Bayardo, R. (Org.) Políticas culturais na IberoAmérica, pp. 19-49. Edufba, Salvador.

Calabre, L. 2009. Políticas culturais: indicadores e informações como ferramentas de gestão pública. Ponencia en la VIII Reunión de Antropología del MERCOSUR (RAM). Universidad Nacional de San Martín, Buenos Aires.

Coelho, T. 2000. Diccionario de política cultural: cultura e imaginario. CONACULTA-ITESO, México.

DaMatta, R. 1987 Cidadania: a questão da cidadania num universo relacional En: A Casa y a Rua. Guanabara, Río de Janeiro.

Fonseca lubel, A. 2009 "O paradoxo os documentos de identidade: relato de uma experiência nos Estados Unidos". Horizontes Antropológicos, Vol. Etnografías, Año 15, $n^{\circ}$ 32, pp. 53-80, PPGAS, Porto Alegre.

Fraenkel, B. 1995 La firma contra la corrupción de lo escrito. En Bottéro J. y otros. Cultura, pensamiento, escritura, pp. 77-95, Gedisa, Barcelona.

Jackson, J. 1990 'I Am a Fieldnote': Fieldnotes as a Symbol of Professional Identity En Roger Sanjek (ed.) Fieldnotes: The Makings of Anthropology, pp. 3-44, Ithaca: Cornell University Press.

Nivón Bolán, E., A. R. Mantecón. 2002. México: la política cultural de los Gobiernos del Distrito Federal 1997-2006. Notas para un balance En Lacarrieu M., Álvarez M. (Comp.). La (Indi) Gestión Cultural. Una Cartografía de los procesos culturales contemporáneos, pp. 175-215, Ediciones Ciccus - La Crujía, Buenos Aires.

O’Donell, G. 1984. Apuntes para una teoría del Estado En Oszlak O. (Comp.) Teoría de la burocracia estatal: enfoques críticos, pp. 199-250, Editorial Paidós, Buenos Aires.

Pantaleón, J. 2005 Entre la carta y el formulario. Política y técnica en el desarrollo social. Buenos Aires: Editorial Antropofagia.

Petit, M. 1999 Nuevos acercamientos a los jóvenes y la lectura. México: Fondo de Cultura Económica.

Rubim, A., I. Oliveira Rubim, M. Pitombo Vieira. 2006 Actores sociais, redes e políticas culturais En Convenio Andrés Bello (CAB) 2, pp. 13-64, Edición del Convenio Andrés Bello, Brasil.

Weber, M. 1985. Burocracia. En Max Weber. Ensayos de sociología contemporánea, 1, pp. 167-232, PlanetaAgostini, Barcelona. 